\title{
Tribocorrosion behavior of Ti-C-O-N nanostructured thin films (black) for decorative applications
}

\author{
P. Lima a , M. Araújo a , M.T. Mathew ${ }^{\mathrm{a}, \mathrm{b}, *}$, L.A. Rocha ${ }^{\mathrm{a}, \mathrm{c}}$, A.M. Pinto ${ }^{\mathrm{a}, \mathrm{d}}$, J.M. Chappé ${ }^{\mathrm{e}}$, \\ M.D. Ramos ${ }^{\text {e, L. Marques }}{ }^{\text {e }}$, J.F. Pierson ${ }^{f}$, F. Vaz ${ }^{\text {e }}$ \\ ${ }^{a}$ Centre for Mechanical and Materials Technologies (CT2M), Azurém, 4800-058 Guimarães, Portugal \\ ${ }^{\mathrm{b}}$ Department of orthopedics, Rush University Medical Center, Chicago, IL- 60612 \\ ${ }^{\text {c } U n i v e r s i d a d e ~ E s t a d u a l ~ P a u l i s t a ~(U n e s p), ~ F a c u l d a d e ~ d e ~ C i e ̂ n c i a s ~ d e ~ B a u r u, ~ S P, ~ 17033-360, ~ B r a z i l ~}$ \\ ' Universidade do Minho, Dept. Eng. Mecânica, Azurém, 4800-058 Guimarães, Portugal \\ e Universidade do Minho, Centro de Física e Dept. Física, Gualtar, 4710-057 Braga, Portugal \\ ${ }^{\mathrm{f}}$ Laboratoire de Science et Génie des Surfaces (UMR CNRS 7570), Ecole des Mines, Parc de Saurupt, CS 14234, 54042 Nancy Cedex, France
}

\section{A R T I C L E I N F O}

\section{Article history:}

Received 16 November 2012

Received in revised form

30 May 2013

Accepted 3 June 2013

Available online 13 June 2013

Keywords:

Tribocorrosion

Thin films

Structural characterization

Materials degradation

\begin{abstract}
In the past few years, tribocorrosion has become a focus of research because of its relevance in terms of the future in-service degradation mechanisms of materials. In the particular case of decorative coatings, tribocorrosion is certainly one of the most important issues, and sweat corrosion and human contact wear are two other factors that may act as material selection tools.

Thus, the current study aimed to investigate the tribocorrosion behavior of a new class of thin films, the Ti-C-O-N system, which is being developed to be used as a surface decorative material due to its relatively dark appearance. The films were prepared by reactive magnetron sputtering. The influence of the structural features on the tribocorrosion behavior is discussed.
\end{abstract}

Crown Copyright @ 2013 Published by Elsevier Ltd. All rights reserved.

\section{Introduction}

In the last ten years, an emergent field of research within thin film technology has gained increasing importance: the so-called multifunctional thin films [1-4]. Among the available studies, the thin film decorative field is yielding unexpected, interesting contributions $[5,6]$. Until recently, these decorative films were mostly based on metallic elemental materials and Me (with Me commonly standing for a transition metal), but binary (nitrides, carbides, borides, among others), ternary and even quaternary-type films are also being developed [7-11]. Nevertheless, due to the increasing demands of modern technological applications, the continuous change in target materials and the deposition process to obtain different decorative films is clearly not suitable. The particular case of electrical applications, where the need to obtain either conductive and/or insulatingtype materials is often required, should be noted [12-14]. Thus, it is necessary to completely change the deposition process, target materials, and gas atmospheres, among other factors. For instance,

\footnotetext{
* Corresponding author at: Rush University Medical Centre Department of Orthopedics Tribology Group, 1926 West Harrison Street, Chicago, IL 60612 United States. Tel.: +1 312942 8310; fax: +1 3129424491 .

E-mail addresses: Mathew_T_mathew@rush.edu, mathew@dem.uminho.pt (M.T. Mathew).
}

a single metallic film (copper, titanium, etc.) or a nitride/carbide film (TiN, TiC, among others) should exhibit metallic behavior associated with good surface mechanical resistance. Similarly, the process should be tuned towards an oxide-type material (for example $\mathrm{TiO}_{2}$, $\mathrm{ZrO}_{2}$, etc.) to obtain insulating-type materials. Changes should be introduced in the gas atmospheres and the target materials required to produce films varying between conductive (metal or nitride/ carbide) and insulating types of material (for example, an oxide). The corresponding losses of time (an important drawback in industrial environments) and other difficulties related to process implementation are clearly undesirable. Such concerns are mainly related to the study of the new deposition conditions and materials characterization, for example, which might lead to obvious process losses and should therefore be avoided.

In this respect, oxynitrides, $\mathrm{Me}(\mathrm{O}, \mathrm{N})$, and oxycarbides, $\mathrm{Me}(\mathrm{C}, \mathrm{O})$ (where Me stands for one or several metal combinations), are the focus of some research groups because the presence of oxygen in metallic nitrides/carbides, $\mathrm{MeN}_{\mathrm{x}} / \mathrm{MeC}_{\mathrm{x}}$ (again with Me being one or a combination of different metals), allows the tailoring of film properties resembling both those of covalent materials, $\mathrm{MeN}_{\mathrm{x}} /$ $\mathrm{MeC}_{\mathrm{x}}$, and those of the corresponding, largely ionic oxides [15-17]. Tuning the oxide/nitride(carbide) ratio allows for a large spectrum of properties, namely structural, electrical, optical and mechanical properties. Varying the amount of oxygen within the films can 
tune the band-gap, bandwidth and crystallographic order between oxide and nitride and thus alter the electronic properties, which leads to corresponding changes in all material properties $[5,15,16]$. The aim of this project was to determine the influence of oxygen addition to a particular class of hard-metallic nitrides/carbides: Me $(\mathrm{N}, \mathrm{C})$, with $\mathrm{Me}=\mathrm{Ti}$ and $\mathrm{Zr}$.

At present, the available knowledge regarding multifunctional materials (such as the recently developed decorative oxynitride systems $[5,15,18])$ is still very limited, and extensive experimental and theoretical investigations are required. The important findings thus far in terms of changes in the optical $[16,18]$, electrical $[16,18]$ and mechanical [5,15-17] characteristics are clearly insufficient with respect to using these materials in real conditions. In fact, all property changes have been found to be very closely related to the particular composition features and the changes induced in film structure. Electrical measurements, namely electrical resistivity, have clearly indicated that the films range from metallic type at low oxygen contents to insulating type when the oxygen amounts are relatively high $[16,18]$. An interesting cluster of properties was observed for intermediate oxygen doses (and relatively low C contents), in which a mixed structure was developed (a mixed oxide+carbide structure-type) [17], suggesting the possibility of a very wide range of film behavior in very different functional applications.

Due to the specific applications of such films, the wear and corrosion characteristics are important to determining the durability of parts and components. Through a combined approach called tribocorrosion $[19,20]$, many studies have reported the performance of these films for decorative applications [21-24]. Thus, the objective of the current work was to conduct a detailed tribocorrosion investigation of three representative samples from a set of Ti-C-O-N thin films. The three samples represent each of the three zones that were identified in a previous study $[25,26]$.

\section{Experimental details}

\subsection{Film preparation and characterization techniques}

Depositions of titanium oxycarbonitride thin films were performed in a laboratory-size direct current (DC) magnetron sputtering system. The films were prepared with the substrate holder positioned at $70 \mathrm{~mm}$ from the target in all runs, with a discharge current density of $100 \mathrm{~A} . \mathrm{m}^{-2}$ on the titanium target. The substrates (mechanically polished high speed steel AISI M2) were grounded and remained at a constant temperature, $T=473 \mathrm{~K}$ (an external heating resistance positioned at $80 \mathrm{~mm}$ from the substrate holder was used to heat the samples), during a one-hour deposition using an external heating resistance. A thermocouple was placed close to the surface of the "substrate holder" on the plasma side (not in direct contact because depositions were conducted in rotation mode), and the temperature was measured immediately after stopping the discharge. The titanium target (99.96\% purity and a size of $200 \times 100 \times 6 \mathrm{~mm}^{3}$ ) was sputtered in an argon (working gas)+gas mixture (oxygen and nitrogen source)+acetylene (carbon source) atmosphere. The gas mixture was composed of nitrogen and oxygen, with a constant $\mathrm{N}_{2}: \mathrm{O}_{2}$ ratio of 17:3. The $\mathrm{Ar}$ flow and the acetylene flow remained constant at $60 \mathrm{sccm}$ and $5 \mathrm{sccm}$, which correspond to partial pressures of $0.47 \mathrm{~Pa}$ and $0.25 \mathrm{~Pa}$, respectively ("sccm" refers to standard cubic centimeters per minute). The gas mixture partial pressure, $p_{\mathrm{O} 2+\mathrm{N} 2}$, was systematically changed from $9 \times 10^{-2}$ to $4 \times 10^{-1}$ Pa by controlling the gas mixture flow rate (from 2 to $18 \mathrm{sccm}$ ). The base pressure was below $10^{-3} \mathrm{~Pa}$. For this particular study, only three representative samples were selected, based on their specified behavioral differences [25]. In this way, the samples were prepared with a gas mixture partial pressure, $p_{\mathrm{O} 2+\mathrm{N} 2}$, of $9 \times 10^{-2}, 2.2 \times 10^{-1}$, and $4 \times 10^{-1}$ was the pressure selected for this work. The first sample (prepared with a $p_{\mathrm{O} 2+\mathrm{N} 2}$ of $9 \times 10^{-2} \mathrm{~Pa}$ ) was selected based on its relatively higher crystallinity and more metallic-like appearance (higher reflectivity and luminescence). This sample's properties suggest metallic-like behavior, and significant differences from the other films were observed [25], including a more greyish surface tone. At the other extreme, the two other samples (produced with $p_{\mathrm{O} 2+\mathrm{N} 2}$ of $2.2 \times 10^{-1}$ and $4 \times 10^{-1} \mathrm{~Pa}$ ) were selected according to their significantly amorphous nature and very dark tone, but they had significantly different $C$ and $O$ contents, which caused some important variations in their physical behavior $[25,26]$.

The chemical composition of the coatings was investigated with a Cameca SX-50 Electron Probe Micro Analysis (EPMA), operating with an acceleration voltage of $15 \mathrm{keV}$. The elemental quantification was performed by comparing the peak intensity in the sample and in standards for each element and applying a ZAF correction to the results. Ball cratering tests were used to measure the thickness of the films. X-ray diffraction (XRD) experiments were performed with a Siemens D-500 apparatus using a Co $\mathrm{K}_{\square}$ radiation $(\square=0.178897 \mathrm{~nm}$ ) in a Bragg-Brentano configuration. The film color was determined in the CIELab 1976 color space by using a commercial Minolta CM-2600d portable spectrophotometer with diffused illumination (D65 light source) at an $8^{\circ}$ viewing angle (specular component included). The instrument was equipped with a $52 \mathrm{~mm}$ diameter integrating sphere and 3 pulsed xenon lamps. The observer was placed at a $10^{\circ}$ angle. The surface and cross-section morphological features of the films were studied by scanning electron microscopy (SEM) and atomic force microscopy (AFM), whereas surface defects were characterized by optical microscopy (OM). The film hardness and Young's modulus were determined from the loading and unloading curves, which were performed with an ultra low load-depth sensing Berkovich nanoindenter from CSM Instruments (Switzerland). The maximum load used was $30 \mathrm{mN}$, with a loading time of $30 \mathrm{~s}$, a holding time of $30 \mathrm{~s}$ and an unloading time of $30 \mathrm{~s}$, producing an average of 15 indentations per sample. The testing procedure included correction of the experimental results for geometrical defects in the tip of the indenter, the thermal drift of the equipment, and uncertainty in the initial contact. Because the substrate surface was prepared using a similar metallographic method, before film deposition, the anticipated effect of substrate surface conditions on the hardness measurements might have been uniform $[26,27]$.

\subsection{Preliminary corrosion tests}

Before starting the tribocorrosion tests, basic corrosion behaviors of the samples were individually analyzed using a specially made corrosion cell. The open circuit potential (OCP) was monitored for $600 \mathrm{~s}$, and then potentiodynamic polarization tests were conducted in both the substrate and the TiCON films, with a voltage between $-0.8 \mathrm{~V}$ and $+2.0 \mathrm{~V}$ and a scan rate of $2 \mathrm{mV} . \mathrm{s}^{-1}$. A PGP201 Potentiostat/galvanostat (Radiometer analytical, Denmark) controlled by Voltamaster-1 software was used.

\subsection{Tribocorrosion tests}

A schematic diagram of the tribocorrosion experimental setup is shown in Fig. 1. Reciprocating sliding tests were performed in a Plint TE-67/R apparatus supplied by Phoenix Tribology, Ltd. (UK) (previously known as Plint and partners (Ltd)). Tests were conducted with an alumina pin (with truncated cone geometry) sliding on a plate sample (the TiCON films) at a fixed normal load 


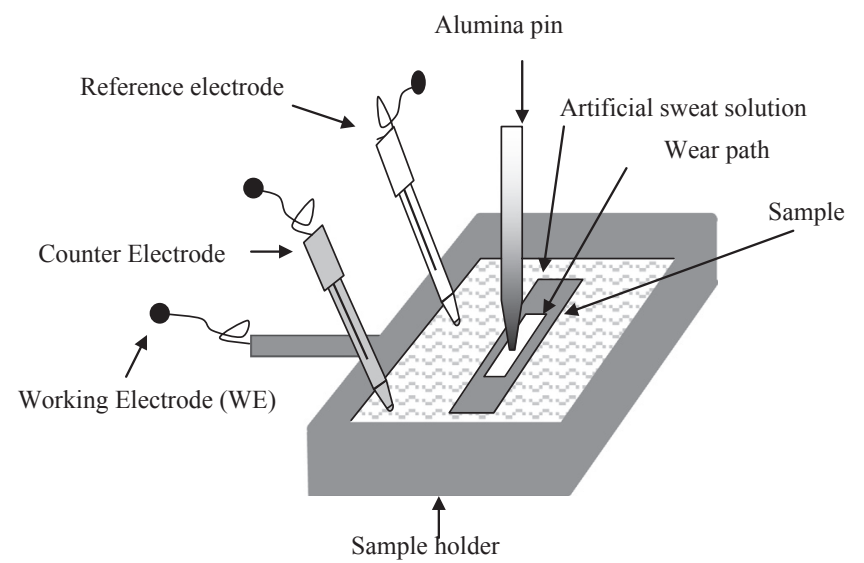

Fig. 1. Schematic diagram of the reciprocating pin/plate tribometer and the electrochemical cell used in the test.

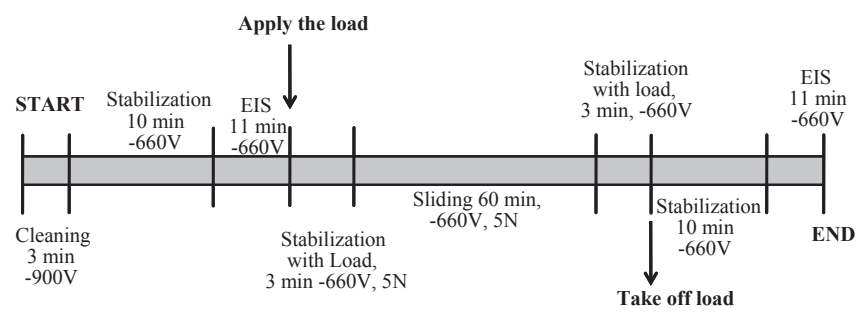

Fig. 2. Experimental protocol used in the test.

of $5 \mathrm{~N}$. The specially made acrylic tribocorrosion cell is also shown in Fig. 1. The sliding stroke length was $6 \mathrm{~mm}$, with a frequency of $1 \mathrm{~Hz}$ and an exposed area of $0.95 \mathrm{~cm}^{2}$. At the beginning of each test, the pin head was polished to maintain a constant diameter of $1 \mathrm{~mm}$ and to achieve consistent contact conditions between the pin and the sample. The electrolyte was composed of an artificial sweat solution. Its composition was as follows: $\mathrm{NaCl}, 7.5 \mathrm{~g} \cdot \mathrm{L}^{-1} ; \mathrm{KCl}$, 1 g.L ${ }^{-1} ; \mathrm{CH}_{4} \mathrm{~N}_{2} \mathrm{O}$ (urea), 1 g.L $\mathrm{L}^{-1}$; and $\mathrm{C}_{3} \mathrm{H}_{6} \mathrm{O}_{3}$ (lactic acid), $1 \mathrm{ml} . \mathrm{L}^{-1}$. $\mathrm{NH}_{3}$ was added to adjust the $\mathrm{pH}$ to $4.49+0.01$. The solution is a simplified version of that established in European Standard EN 1811:1998 [28] and was contained in the acrylic cell, with a volume of approximately $20 \mathrm{ml}$. A standard calomel electrode (SCE) was used as a reference electrode, and a platinum wire was used as a counter electrode. The sample of TiCON film was connected to the working electrode.

The standard protocol used for the test is shown in Fig. 2. Prior to all tribocorrosion experiments, the samples were cathodically polarized at $-900 \mathrm{mV}$ vs. SCE for $180 \mathrm{~s}$ for cleaning purposes. Furthermore, to stabilize the sample, a potential of $-660 \mathrm{mV}$ was applied for $600 \mathrm{~s}$ and then maintained during the entire test. Then, electrochemical impedance spectroscopy (EIS) was performed in the frequency range of $100 \mathrm{kHz}$ to $15.82 \mathrm{mHz}$, with an ac sine wave amplitude of $10 \mathrm{mV}$ applied to the electrode, maintaining the sample under potentiostatic control, i.e., $-660 \mathrm{mV}$ ( $\mathrm{E}_{\text {corr }}$ of the steel). The alumina pin was brought into contact with the plate sample. The reciprocating sliding tests were conducted for $3600 \mathrm{~s}$. An EIS test was performed at the end of the experiment after stabilization of the sample. At the end of the test, the pin and the sample were ultrasonically cleaned by propanol and distilled water. Each experiment was repeated twice, with an expected error of 5-7\%. Z-View software was used for EIS data simulation. The wear volume was determined by profilometry using a Perthometer S5P surface measuring and recording instrument; the cross-sectional area and stroke length were measured. The cross sectional area and depth of the wear profiles were measured using AutoCAD 2006 software [23,24].

\section{Results and discussion}

\subsection{Structural and mechanical characterization of the film}

The selection of the three samples from a relatively large set of other samples was based on their particular characteristics so that their behavior was representative $[25,26]$. The overall set of samples showed a wide variation in element concentration (Ti, C, O and $\mathrm{N}$ ), which induced a change in the film structure from the crystalline type to the amorphous type, with a consequent variation in the other film properties, such as the optical properties, which are the main targeted application of these films [25,26]. In fact, these samples are mainly intended to be used for decorative purposes because they have very dark tones, and thus, a systematic study of the different behaviors observed in the overall set (which was carried out here using the three samples that best represent these behaviors) is important for understanding corrosion and wear, which are the key properties pertaining to the use of such coatings.

\subsubsection{Composition and crystalline structure of the samples}

Fig. 3 ( $a$ and $b$ ) shows the composition results obtained using EPMA on the three $\mathrm{Ti}(\mathrm{C}, \mathrm{O}, \mathrm{N})$ samples (with thicknesses ranging from 1 to $1.8 \square \mathrm{m}$ ) selected for this study; the data are plotted as a function of the reactive gas flows ratio. Fig. 3(a) shows the variation in the atomic concentration of the film elements as a function of the reactive gas flows ratio, whereas Fig. 3(b) presents the metalloid over titanium atomic ratios, $\mathrm{C}_{\mathrm{C}} / \mathrm{C}_{\mathrm{Ti}}, \mathrm{C}_{\mathrm{O}} / \mathrm{C}_{\mathrm{Ti}}, \mathrm{C}_{\mathrm{N}} / \mathrm{C}_{\mathrm{Ti}}$ and
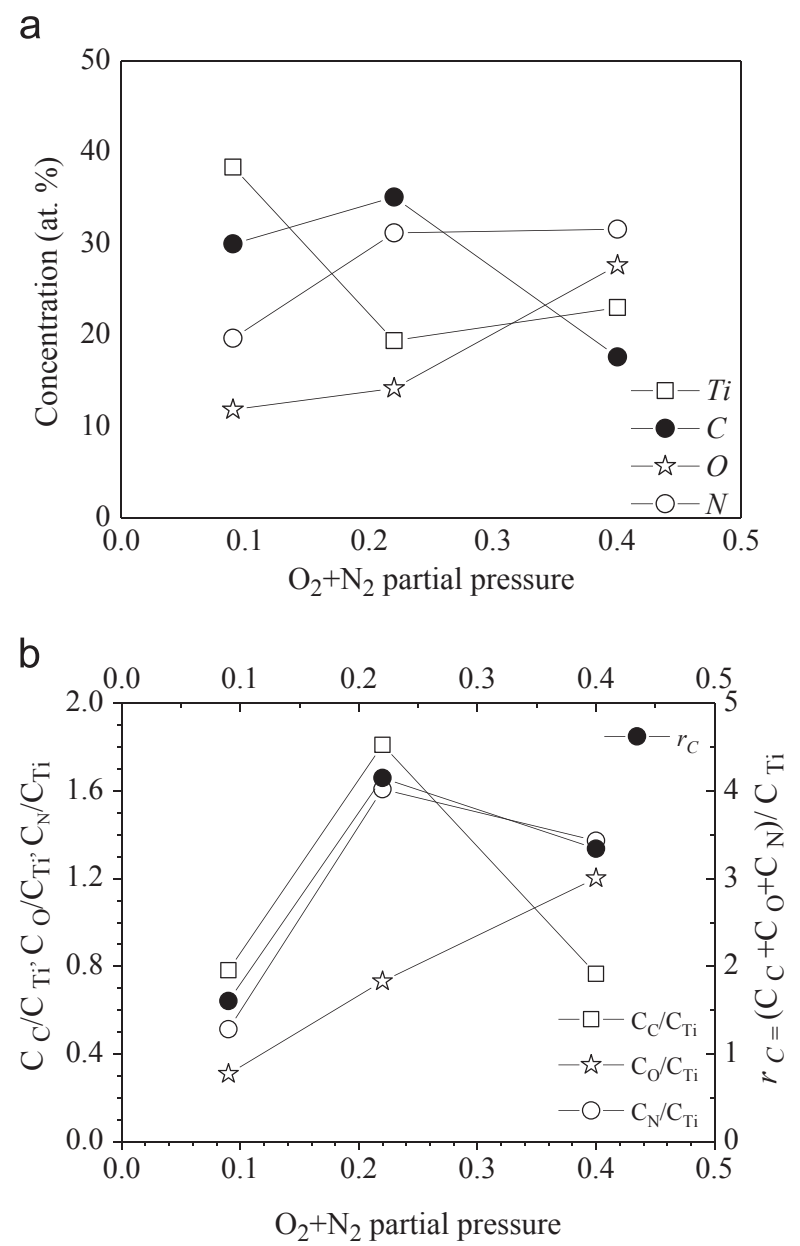

Fig. 3. Properties of the selected films. (a) Variation in the atomic concentration of the film elements as a function of the reactive gas flows ratio. (b) Presentation of the metalloid over the titanium atomic ratios, $\mathrm{C}_{\mathrm{C}} / \mathrm{C}_{\mathrm{Ti}}, \mathrm{C}_{\mathrm{O}} / \mathrm{C}_{\mathrm{Ti}}, \mathrm{C}_{\mathrm{N}} / \mathrm{C}_{\mathrm{Ti}}$ and $\left(\mathrm{C}_{\mathrm{C}}+\mathrm{C}_{\mathrm{O}}+\mathrm{C}_{\mathrm{N}}\right) / \mathrm{C}_{\mathrm{Ti}}$. 
$\left(\mathrm{C}_{\mathrm{C}}+\mathrm{C}_{\mathrm{O}}+\mathrm{C}_{\mathrm{N}}\right) / \mathrm{C}_{\mathrm{Ti}}$. For simplicity, the different samples are denoted throughout the text according to their $\left(C_{C}+C_{O}+C_{N}\right) / C_{T i}$ atomic ratio, $r_{\mathrm{C}}$, due to the significance that this ratio has on film properties and because it appears to represent the different samples in terms of their particular composition features well $[15,16]$. According to Fig. 3(a), the first conclusion to be drawn is that the three samples in fact have very different compositions and vary significantly. As expected, the sample prepared with the lowest oxygen $(\mathrm{O})+$ nitrogen $(\mathrm{N})$ partial pressure $\left(9 \times 10^{-2} \mathrm{~Pa}\right)$, $\mathrm{TiC}_{0.78} \mathrm{O}_{0.31} \mathrm{~N}_{0.51}$, has the highest Ti concentration ( $\sim 39$ at. \%) but the lowest $\mathrm{O}$ (about 12 at. \%) and $\mathrm{N}(\sim 20$ at. \%) concentrations. However, the sample prepared with the highest oxygen+nitrogen partial pressure $\left(4 \times 10^{-1} \mathrm{~Pa}\right), \mathrm{TiC}_{0.77} \mathrm{O}_{1.20} \mathrm{~N}_{1.37}$, has a relatively high oxygen content ( $\sim 28$ at. \%) and the lowest C content (about 18 at. \%). Ti is relatively low (close to 23 at. \%), whereas the N content is the highest $(\sim 32$ at. \%) and very similar to that of the sample prepared with an intermediate oxygen+nitrogen partial pressure $\left(2.2 \times 10^{-1} \mathrm{~Pa}\right), \mathrm{TiC}_{1.81} \mathrm{O}_{0.73} \mathrm{~N}_{1.61}$. Although it may be somewhat difficult to find a trend, the plot of the atomic ratios indicates some variation trends. Fig. 3(b) shows the evolution of the atomic ratios of the different samples, namely $r_{c}$.

The figure shows that the evolution of $r_{c}$ is quite similar to that of $\mathrm{C}_{\mathrm{N}} / \mathrm{C}_{\mathrm{Ti}}$ and has the same variation tendency as $\mathrm{C}_{\mathrm{C}} / \mathrm{C}_{\mathrm{Ti}}$. Due to its higher reactivity, oxygen increases steeply for all samples. This increase is not too high, though, which is indicative of the fact that no oxide-like samples were obtained (all samples revealed intrinsic colors; black tones were observed for the two prepared with the highest gas mixture partial pressures). Of particular note is the variation in the $r_{c}$ ratio, which significantly increases from approximately 1.6 for the sample prepared with the lowest gas mixture partial pressure, $\mathrm{TiC}_{0.78} \mathrm{O}_{0.31} \mathrm{~N}_{0.51}$, which has composition combination similar the stoichometric condition $\mathrm{Ti}_{1.0}(\mathrm{C}, \mathrm{O}, \mathrm{N})_{1.0}$, to values above 3.3 and 4.1 for the samples prepared with the highest gas mixture partial pressures $\left(4 \times 10^{-1} \mathrm{~Pa}\right.$ for $\mathrm{TiC}_{0.77} \mathrm{O}_{1.20} \mathrm{~N}_{1.37}$ and $2.2 \times 10^{-1} \mathrm{~Pa}$, for $\mathrm{TiC}_{1.81} \mathrm{O}_{0.73} \mathrm{~N}_{1.61}$ ). These samples thus demonstrate a significant over-stoichiometric condition. This condition has a significant effect on the film properties, particularly the structural properties, which in turn have a significant effect on all other film properties, such as the physical properties, as reported previously $[25,27]$; other important properties, such as the tribological and mechanical properties, are also affected if the films are used decorative applications.

Furthermore, although the two samples prepared with the highest gas mixture partial pressures have high $r_{c}$ ratio values, it is important to note that there are significant differences between them. Let us recall that the sample prepared with a gas mixture partial pressure of $2.2 \times 10^{-1}$ Pa has a C content that is approximately twice as high as that of the sample prepared with a partial pressure of $4 \times 10^{-1} \mathrm{~Pa}(\sim 35$ at. \% in the first and about 17.6 at. \% in the second) but simultaneously an $O$ content that is half as high (14 at. \% in the first and $\sim 28$ at. \% in the second). Again, these changes may have some effect on the film properties, particularly the tribological properties, as expected based on the $\mathrm{C}$ content differences.

\subsubsection{Structural, morphological and mechanical behavior}

As expected and as previously noted, all of the aforementioned differences in the composition evolution have a clear influence on the structural properties, as demonstrated in Fig. 4. This figure shows that there is a major difference between the closestoichiometric sample $\left(r_{c}=1.6\right)$ and the highly overstoichiometric samples $\left(r_{c}=3.3\right.$ and $\left.r_{c}=4.1\right)$. In the first case, most likely due to its close stoichiometry, the XRD results show the development of a roughly crystalline sample, whose diffraction patterns seem to correspond to a face centered cubic-type structure, with a lattice parameter on the order of $0.429 \mathrm{~nm}$. The exact

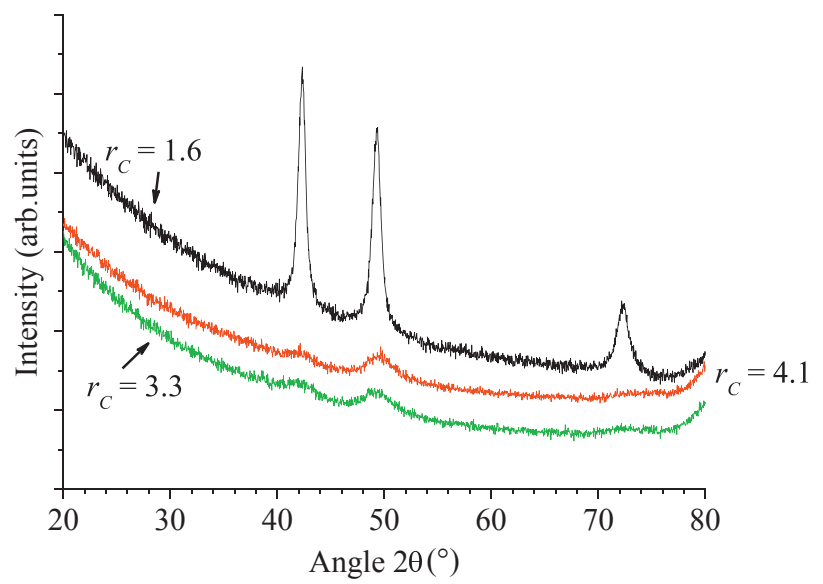

Fig. 4. Structural properties of the three films, with $r_{c}$ values of $1.6,3.3$ and 4.1.

nature of this cubic phase is quite difficult to index, but the value of the lattice parameter may give some indications. The lattice parameters for the known binary compounds TiO, TiN and TiC are $a_{\mathrm{TiO}}=0.4177 \mathrm{~nm}$ for JCPDS04-001-6834, $a_{\mathrm{TiN}}=0.4241 \mathrm{~nm}$ for JCPDS04-001-2272 and $a_{\mathrm{TiC}}=0.4328 \mathrm{~nm}$ for JCPDS04-004-2919, respectively. Although still not conclusive, the most probable hypothesis is that this $r_{c}=1,6$ sample has a solid solution-type structure, where $\mathrm{C}, \mathrm{O}$ and $\mathrm{N}$ co-exist in the same lattice, which would explain the intermediate lattice parameter of this sample. However, there is still the possibility of some interstitials, but in that case, a relatively higher lattice parameter would be expected, given the large amounts of both $\mathrm{C}$ and $\mathrm{N}$ and the lattice parameters of their binary compounds ( $\mathrm{TiC}$ and TiN, respectively). Another possibility, which is supported by the higher oxygen reactivity, is that some excess of $\mathrm{C}$ may also be in an amorphous phase surrounding the crystalline grains that were formed (which could also include some extra C). This amorphous ("isolated") $\mathrm{C}$ seems to be reinforced by Raman spectroscopy [19,20].

Regarding the two highly over-stoichiometric samples, the main finding is that they are quasi-amorphous, which is expected due to the significant lattice distortions that occur due to the excess of nonmetalloid content. Even if one considers the possibility that all $\mathrm{C}$ could be in an amorphous, isolated phase, the amounts of both $\mathrm{O}+\mathrm{N}$ are already between 2.3 and 2.6, significantly above the possible cubic-type stoichiometry in the previous sample. Nevertheless, there appear to be a few crystals, and even some lattice parameter distribution, which can be attributed to a mixture of different types of $\mathrm{Ti}(\mathrm{O}, \mathrm{N})$ cubic lattices, with or without $\mathrm{C}$. The fact that no significant differences occur in these two last samples (neither in terms of a roughly amorphous nature nor in terms of peak shapes and positions and even the parameter distribution) means that the $C$ differences in these two samples do not play a major role (35 and 17.6 at. \% as previously mentioned), which may reinforce the idea of the positioning of $\mathrm{C}$ in an isolated $\mathrm{C}$ phase within grain boundaries. Given the well-known effect of C-based films in terms of tribological properties [16,23,29-32], these differences may be important with respect to tribological behavior.

The mechanical properties of the film were studied as a function of the composition ratio $\left(r_{c}\right)$. First, the evolution of the deposition rate as a function of the composition ratio is shown in Fig. 5(a). The deposition rate is significantly reduced as the composition ratio increases, which is a consequence of the significant target poisoning due to the increase in the reactive gases [25]. The variation of hardness and modulus with composition ratio is shown in Fig. 5(b). The hardness value is highest for an $r_{c}$ value of 1.6 and decreases significantly at higher values of $r_{c}$, which is certainly a result of the loss of crystallinity in the samples, as can be easily observed from 


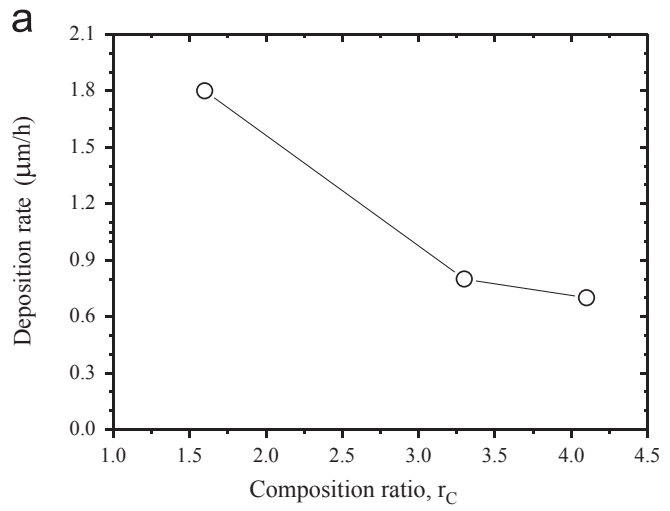

b
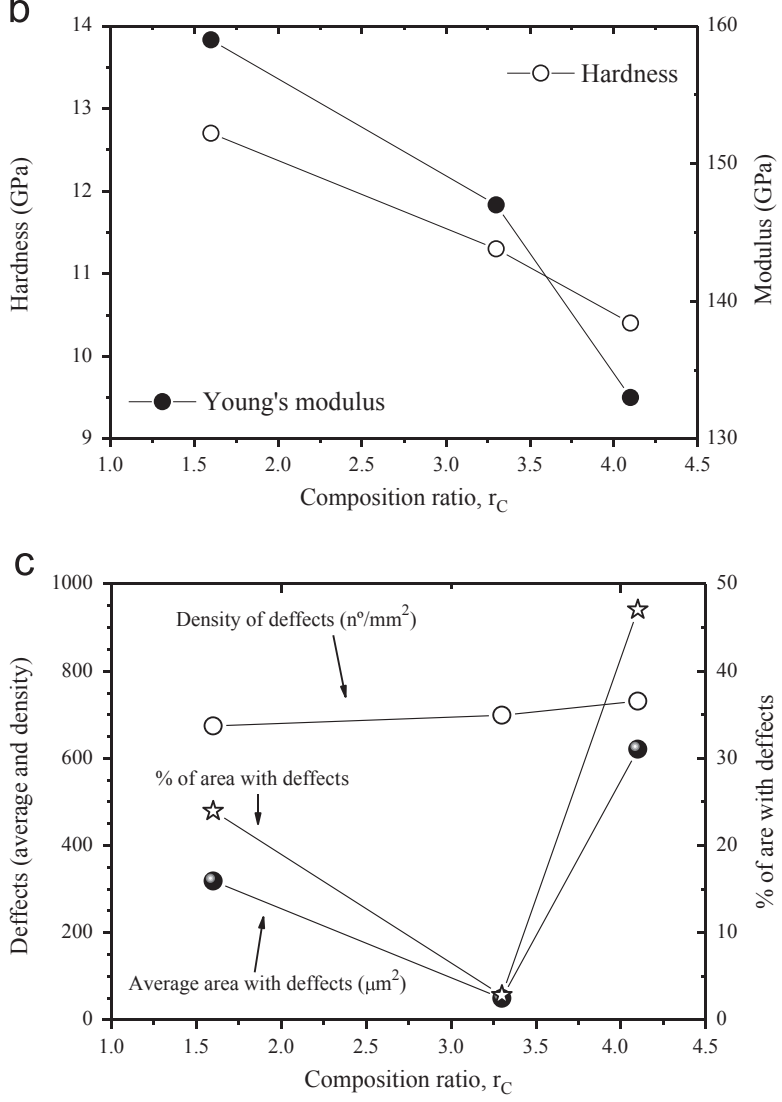

Fig. 5. Properties of the films as a function of $r_{c}$. (a) Thickness of the film as a function of the composition ratio, $r_{c}$. (b) Hardness and young modulus as a function of composition ratio, $r_{c}$. (c) Variation in defects as a function of composition ratio, $r_{c}$.

Fig. 4 [25]. Because of the film is used for decoration, an attempt to estimate the average number of surface defects was also made; the number of defects is an important parameter to consider for the specific tribocorrosion behavior of each representative sample. It is interesting to note that the sample with an $r_{c}$ ratio of 3.3 shows the lowest number of surface defects. The change in growth modes resulting from the combination of the selected deposition parameters is certainly dominating this specific behavior. The transition between the high deposition rate observed in the $r_{c}=3.3$ sample towards a very low rate in the sample prepared at $r_{c}=4.1$ may explain this change in surface defects.

\subsection{Initial corrosion tests}

The basic corrosion behavior was studied using the potentiodynamic curves as shown in Fig. 6. This figure clearly shows that that

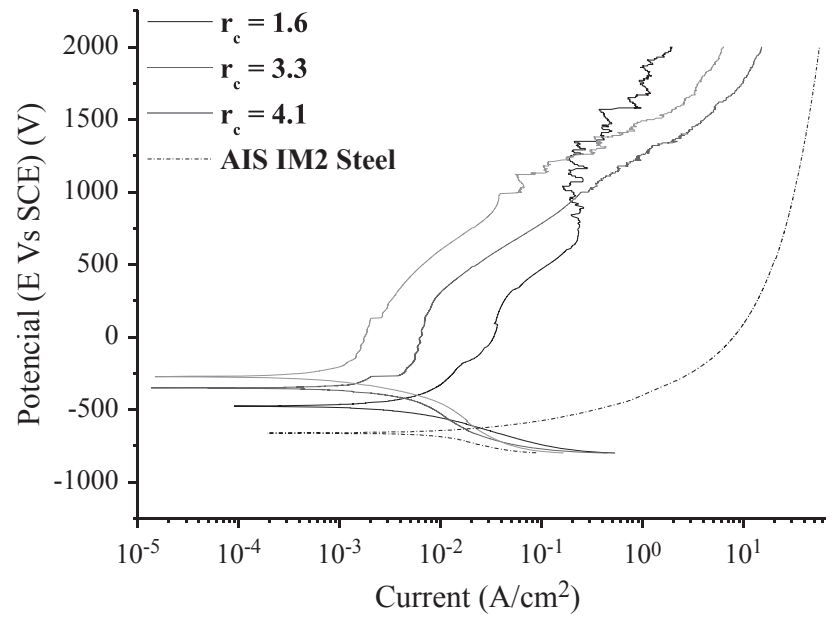

Fig. 6. Potentio-dynamic curves for the TiCNO films and the substrate materials.

the coated substrates exhibit better behavior than the substrate alone. Furthermore, Fig. 6 shows that, based on a comparison of the three representative samples, the film with an atomic ratio $r_{c}$ of 4.1 has the best corrosion behavior. However, in this same sample, a pitting potential above $+0.1 \mathrm{~V}$ leads to a sudden increase in the corrosion current, which may be due to the large number of surface defects of this sample, as demonstrated by the results plotted in Fig. 5(c). It is also important to note that the sample with an atomic ratio $r_{c}$ of 1.6 exhibits behavior that indicates an early pitting potential $(+0.7 \mathrm{~V})$ and the presence of pits.

\subsection{Tribocorrosion performance}

As explained in the experimental details section, the tribocorrosion tests follow a specific protocol, which helps to understand the electrochemical response of the samples before, during and after the sliding tests. Some attempts were also made to correlate the tribological response (friction coefficient) with the evolution of the current, which can help to identify the mechanisms involved in the synergistic interaction between corrosion and wear. Thus, the evolution of the current density and the friction coefficient values during the tribocorrosion tests were analyzed for each film. Fig. 7 shows representative curves of the observed trends for the sample prepared with an atomic ratio $r_{c}$ of 1.6. As can be observed in the plot, the current density decreases very gradually with as the sliding time increases. The accumulation of wear debris and corrosion products in the contact zone could be the reason for the reduction in the current density during the sliding process. Table 1

Studies on the tribocorrosion behavior of $\mathrm{Fe}-1 \mathrm{Cr}$ in acidic and alkaline solutions have indicated that the instantaneous current is a periodic function in a reciprocating sliding tribometer and depends on the motion of the pin, which moves at a constant speed during a forward stroke and then remains stationary for a few milliseconds before changing its direction [15]. During the rest period, the current decreases due to repassivation and then increases again when the pin starts to return. The main concern in wear-corrosion studies on the current setup is that the reciprocating pin motion creates nonsteady electrochemical conditions at the contact zone [19-21]. However, electrochemical interfacing techniques favor stationary conditions during testing [29-32]. Thus, the dynamic and transient conditions at the contact zone might influence the results obtained. The friction coefficient values are also observed to be very sensitive to the sliding process, Fig. 7. Generally, the values of the friction coefficients remain stable after an initial running-in period [23]. 


\subsection{Electrochemical impedance spectroscopy (EIS) analysis}

\subsubsection{Bode plots}

Electrochemical impedance spectroscopy (EIS) tests were conducted before and after the sliding tests to understand the changes in the surface chemistry of the tested sample. In fact, EIS tests can indicate the electrical properties of the film and the double layer formed on its surface during the corrosion process. The technique normally involves the use of a typical threeelectrode system and a small-amplitude AC voltage $(+-10 \mathrm{mV})$ that is applied to the working electrode to measure the current responses flowing through the electrode. The AC potential and current responses are then passed to a frequency response analyzer to calculate the impedance and phase shift.

Fig. 8 shows bode impedance plots (frequency vs. impendence) and a bode phase plot (Frequency vs. phase angle) for the three representative TiCNO films before and after sliding processes. Fig. 9( $\mathrm{a}$ and b) presents the Bode phase plot (frequency vs. phase angle) before and after sliding.

As can be observed in both figures, the electrochemical behavior of the films is slightly altered after the sliding process, showing a good corrosion behavior at the tested potential. Finally, in accordance with the electrochemical polarization results, the EIS results showed that the corrosion properties do not have a clear dependence on the film thickness and/or the presence of defects, as can be observed in Fig. 9(a) and (b). These results support the idea that the corrosion properties are primarily dependent on the structural properties of the films; further explanations are provided in section 3.9.

\subsubsection{EIS model}

The results of the EIS experiment were modeled by an electrochemical equivalent circuit, which describes the corrosion behavior of each sample. In this work, a simple equivalent circuit composed of the electrolyte or solution resistance $\left(R_{S}\right)$ in series with a constant phase element (CPE) and in parallel with the polarization resistance $\left(R_{p}\right)$ is proposed. The impedance of a CPE is

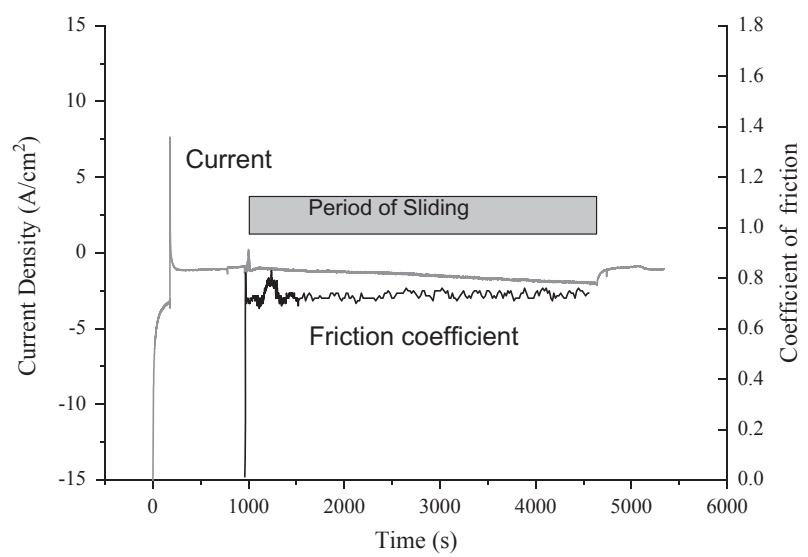

Fig. 7. Tribocorrosion process, evolution of current and friction coefficients. defined by $Z_{\mathrm{CPE}}=1 /\left((\mathrm{jw})^{\mathrm{n}} \mathrm{C}\right)$, where $\mathrm{j}=\sqrt{ }(-1)$ and $w=2 \pi \mathrm{f}$, and the exponent ' $n$ ' of the CPE is related to the non-equilibrium current distribution due to surface roughness [24,25]. The parameter ' $C$ ' is a constant, representing true capacitance of the oxide barrier layer. The results of EIS data simulations are presented in Figs. 10 and 11 and Tables 2 and 3. Good agreement between the fitted and the experimental data was obtained.

The parameter $R_{s}$ represents the average solution resistance and has a value of $145 \Omega . \mathrm{cm}^{2}$ (the range is $\left(135-150 \Omega . \mathrm{cm}^{2}\right.$ ), irrespective of whether it was measured before or after sliding. The polarization resistance, $R_{p}$, shows an increasing trend as a function of composition ratio. It is interesting to note that $R_{p}$ values after the sliding are approximately half of those before sliding, which demonstrates the film removal and the subsequent effect created after the sliding.

The $C$ values are similar for the films with an atomic ratio $r_{c}$ of 1.6 and 4.1. However, in the case of $r_{c}=3.3$, the sample exhibits a very high value, possible due to having the lowest number of defects (see Fig. 5(c)). The slight increase in the $C$ values after
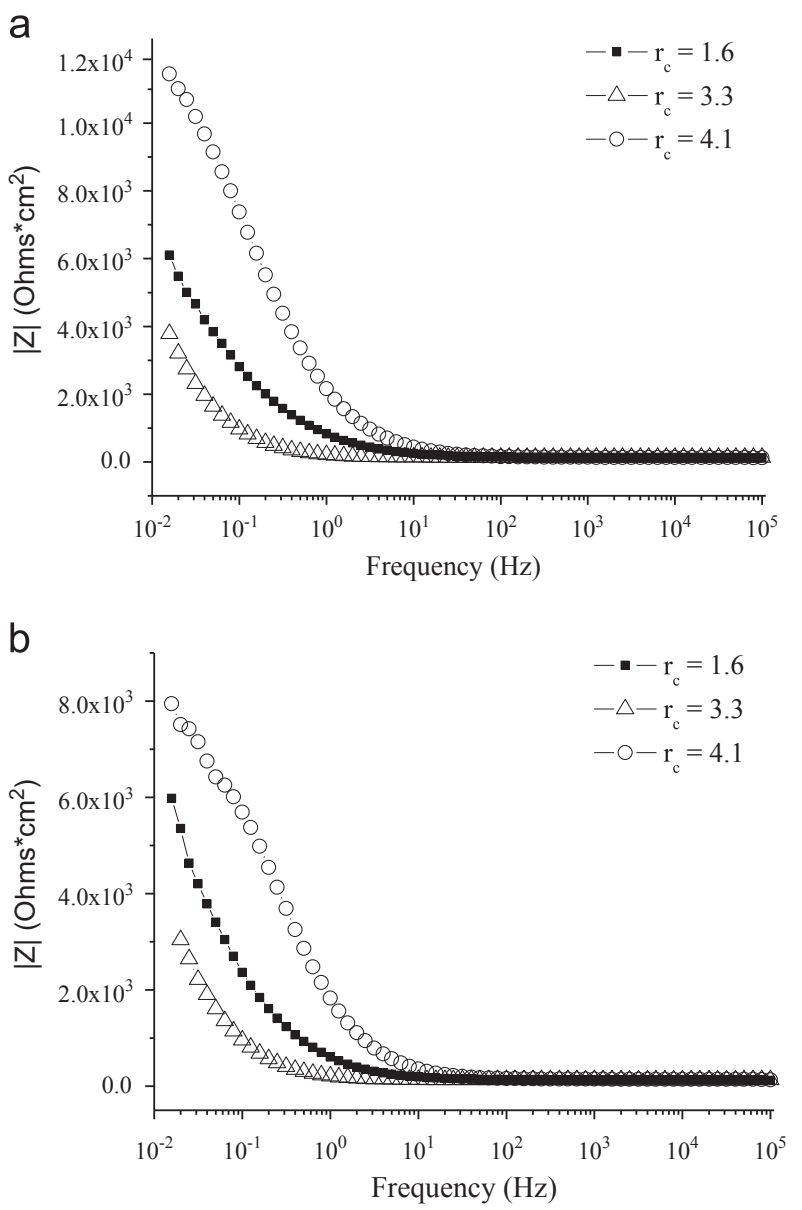

Fig. 8. Bode plot (phase angle vs. frequency). (a) Before sliding. (b) After sliding.

Table 1

Summary of the characteristics of the three representative thin films.

\begin{tabular}{|c|c|c|c|c|c|c|c|}
\hline \multirow[t]{2}{*}{ Sample } & \multicolumn{4}{|c|}{ Chemical composition (at. \%) } & \multirow[t]{2}{*}{ Thickness ( $\mu \mathrm{m})$} & \multirow[t]{2}{*}{ Hardness (GPa) } & \multirow[t]{2}{*}{ Surface defects $\left(\mathrm{n} \% / \mathrm{mm}^{2}\right)$} \\
\hline & $\mathbf{T i}$ & C & $\mathbf{0}$ & $\mathbf{N}$ & & & \\
\hline $\mathrm{TiC}_{0.78} \mathrm{O}_{0.31} \mathrm{~N}_{0.51}$ & 38.41 & 30.02 & 11.88 & 19.69 & 1.8 & 12.7 & 674.3 \\
\hline $\mathrm{TiC}_{0.77} \mathrm{O}_{1.20} \mathrm{~N}_{1.37}$ & 23.04 & 17.63 & 27.68 & 31.64 & 0.8 & 11.3 & 698.5 \\
\hline $\mathrm{TiC}_{1.81} \mathrm{O}_{0.73} \mathrm{~N}_{1.61}$ & 19.42 & 35.15 & 14.21 & 31.23 & 0.7 & 10.4 & 730.9 \\
\hline
\end{tabular}



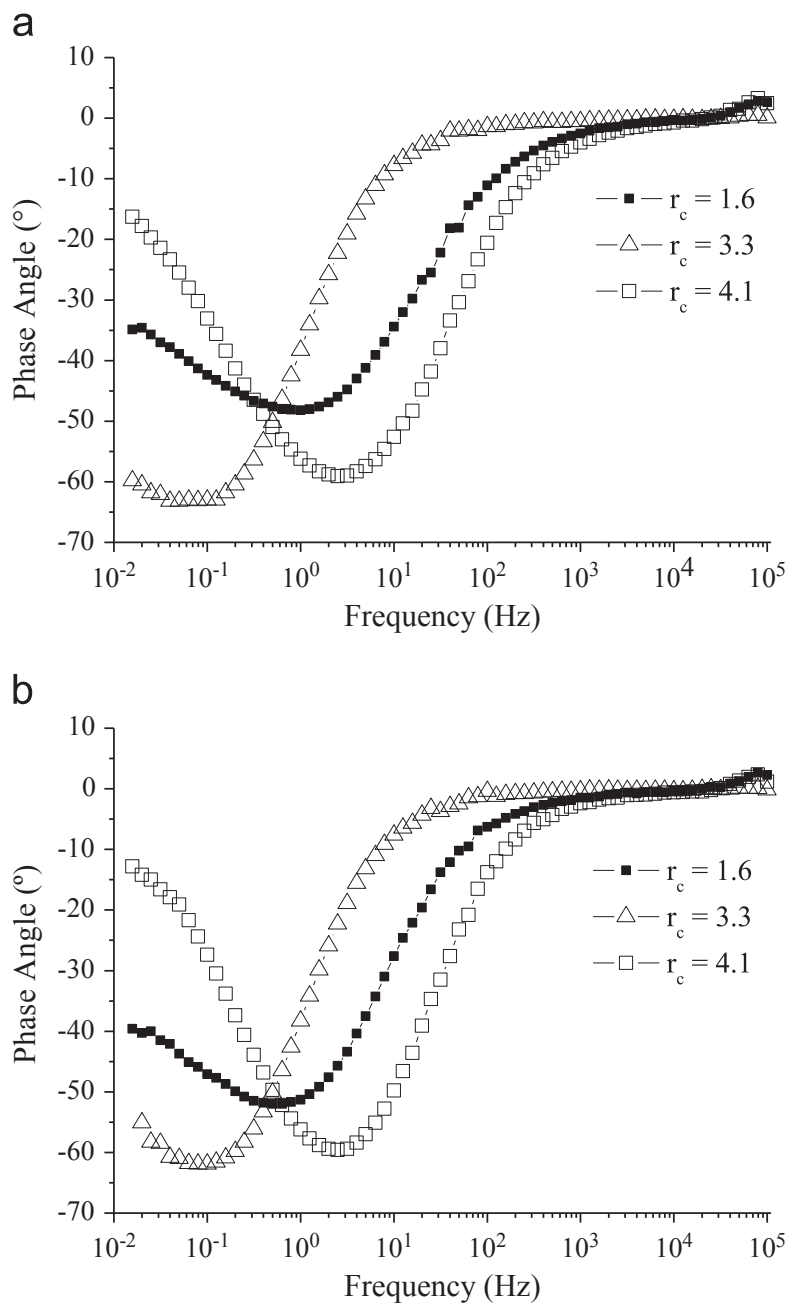

Fig. 9. Bode plot (phase angle vs. frequency). (a) Before sliding. (b) After sliding.

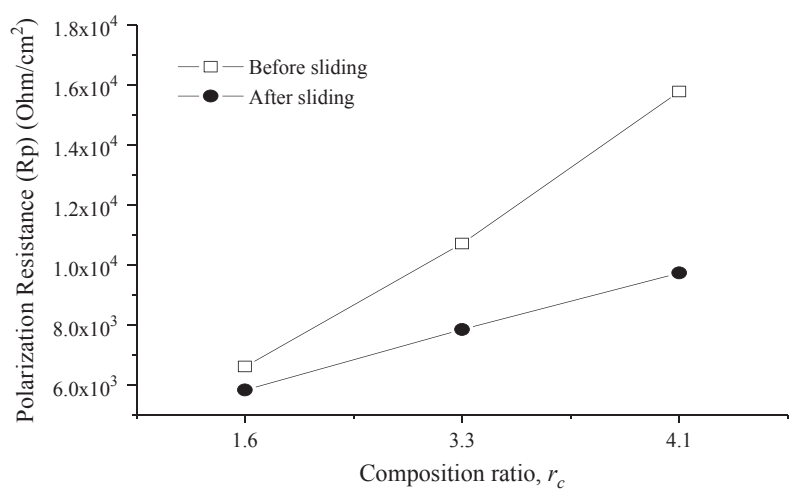

Fig. 10. Variation in polarization resistance $\left(R_{p}\right)$ for the selected films before and after sliding.

sliding are most likely due to the accumulation of wear debris and corrosion products from the complete destruction of the film [23-24]. The values of $n$, which are almost constant in all conditions, were found to be in the range of 0.6-0.7, indicating that the corrosion interface deviated from a perfect ideal capacitor [16]. The theoretical model predictions are in good agreement with the experimental data (the percentage of error is below 6\%; see Table 3). From the EIS analysis, it is clear that the passive oxide layer on the film surface becomes more porous and the resistance

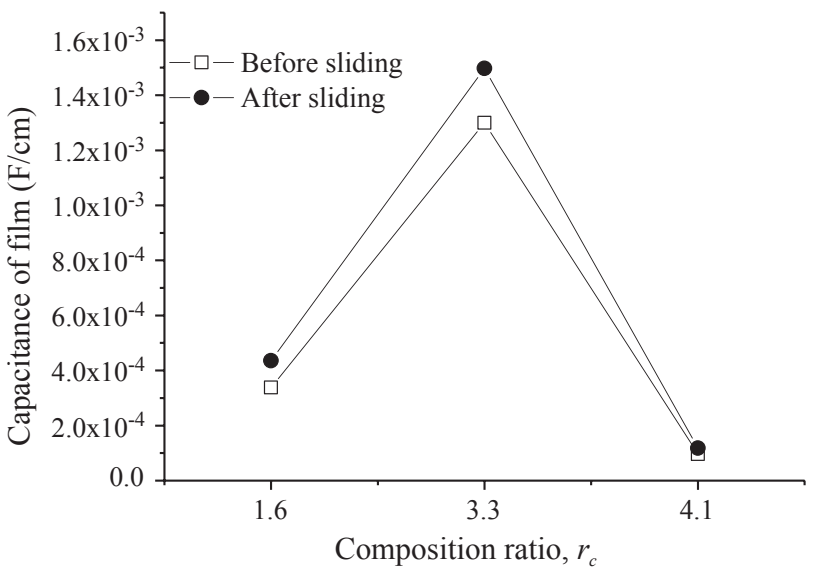

Fig. 11. Variation in film capacitance $\left(C_{f}\right)$ for the selected films before and after sliding.

to charge transfer decreases at the corrosion interface [23]. It is also clear that the best corrosion behavior is exhibited by the sample with an atomic ratio $r_{c}$ of 4.1 at the used corrosion potential. The structure of the film has also a strong influence on the EIS results, as explained in detail in a previous work [23].

\subsection{Surface and morphological characterization}

The worn surfaces were studied using optical microscopy (OM) and scanning electron microscopy (SEM), and the results are shown in Fig. 12. Fig. 12 (a) shows the presence of pits (sample with an atomic ratio $r_{c}$ of 4.1), and Fig. 12(b) is a magnified image. A clear wear track is observed in Fig. 12 (c). Furthermore, the zig-zag boundary of the wear track becomes clear in Fig. 12 (d). The effect of the corrosion is also clear in the SEM image of the pit in Fig. 12 (e); Fig. 12 (f) is an enlarged view.

\subsection{Variation in wear volume with hardness and film thickness}

Variations in the wear and corrosion volume loss in the selected samples are shown in Fig. 13. This figure shows that the samples with atomic ratios $r_{c}$ of 1.6 and 4.1 have approximately the same wear-corrosion volume loss values, and the sample with an atomic ratio $r_{c}$ of 3.3 has a high wear and corrosion volume value. The relationship between the wear-corrosion volume loss and the hardness [33-36] is shown in Fig. 13. The low hardness $\left(r_{c}\right.$ of 3.3) is consistent with high wear-corrosion volume loss; however, it is difficult to define a clear correlation between the hardness and the degradation process [35].

To achieve the optimum wear-corrosion behavior for the different types of films with different thicknesses, it would be ideal to relate the film thickness (Fig. 5(a)) and the wear track depth. The evolution of the wear corrosion volume as a function of film thickness is shown in Fig. 14. From these results, it is easy to verify that the samples with $r_{c}$ values of 1.6 and 4.1 are very similar in terms of their wear-corrosion volume loss and hardness values, but the sample with $r_{c}=4.1$, which is the one with the lowest thickness value, is the one with the highest resistance against wear and corrosion. Thus, the structural and morphological features play a decisive role in this behavior. In fact, the initial corrosion results also agree with this conclusion.

The sample with an atomic ratio $r_{c}=3.3$ is the one that shows the maximal difference in film thickness and wear scar depth. In other words, this sample has higher wear depth and lower thickness. This result is somewhat expected due to the lower thickness value. Poor corrosion behavior leads to a higher wear volume loss. 
Table 2

Electrochemical parameters before sliding.

\begin{tabular}{|c|c|c|c|c|c|c|c|c|}
\hline & \multicolumn{2}{|c|}{$R_{\text {solution }}$} & \multicolumn{2}{|l|}{$C p$} & \multicolumn{2}{|l|}{$N$} & \multicolumn{2}{|l|}{$R_{\mathrm{film}}$} \\
\hline & Value & \% Error & Value & $\%$ Error & Value & \% Error & Value & \% Error \\
\hline $\mathrm{TiC}_{0.78} \mathrm{O}_{0.31} \mathrm{~N}_{0.51}$ & 136.7 & 0.2244 & 0.000338 & 0.78665 & 0.6887 & 0.34188 & 6626 & 3.1674 \\
\hline $\mathrm{TiC}_{0.77} \mathrm{O}_{1.20} \mathrm{~N}_{1.37}$ & 138.6 & 0.28179 & $9.55 \mathrm{E}-05$ & 1.0012 & 0.79327 & 0.31581 & 9923 & 3.1326 \\
\hline $\mathrm{TiC}_{1.81} \mathrm{O}_{0.73} \mathrm{~N}_{1.61}$ & 137 & 0.09542 & 0.014923 & 0.21388 & 0.84 & 0.16714 & 10725 & 3.46 \\
\hline
\end{tabular}

Table 3

Electrochemical parameters after sliding.

\begin{tabular}{|c|c|c|c|c|c|c|c|c|}
\hline & \multicolumn{2}{|c|}{$R_{\text {solution }}$} & \multicolumn{2}{|l|}{$C p$} & \multicolumn{2}{|l|}{$N$} & \multicolumn{2}{|l|}{$R_{\text {film }}$} \\
\hline & Value & \% Error & Value & \% Error & Value & \% Error & Value & \% Error \\
\hline $\mathrm{TiC}_{0.78} \mathrm{O}_{0.31} \mathrm{~N}_{0.51}$ & 136.7 & 0.20501 & 0.000436 & 0.82371 & 0.74844 & 0.3691 & 5844 & 4.2594 \\
\hline $\mathrm{TiC}_{0.77} \mathrm{O}_{1.20} \mathrm{~N}_{1.37}$ & 150.8 & 0.24681 & 0.0001063 & 0.82642 & 0.83074 & 0.2759 & 7233 & 1.7858 \\
\hline $\mathrm{TiC}_{1.81} \mathrm{O}_{0.73} \mathrm{~N}_{1.61}$ & 136.2 & 0.07251 & 0.0014979 & 0.17926 & 0.84644 & 0.13719 & 7856 & 2.4273 \\
\hline
\end{tabular}

a

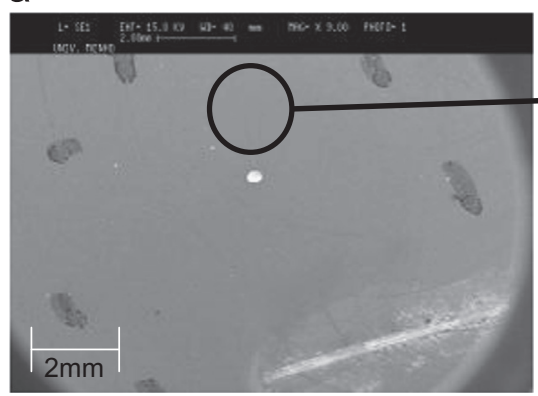

C

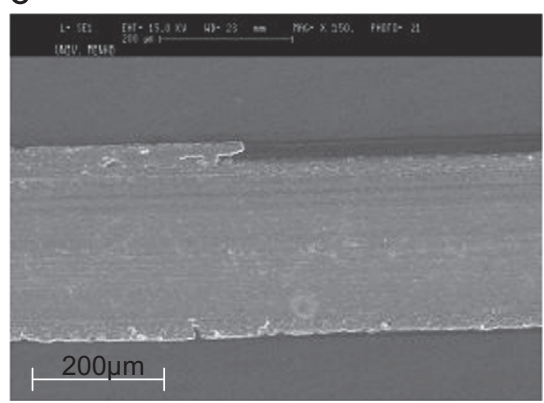

e

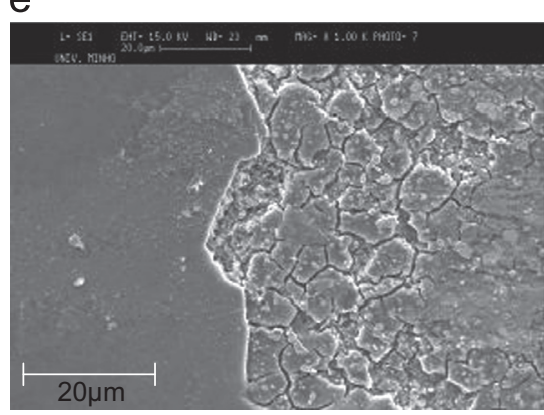

b

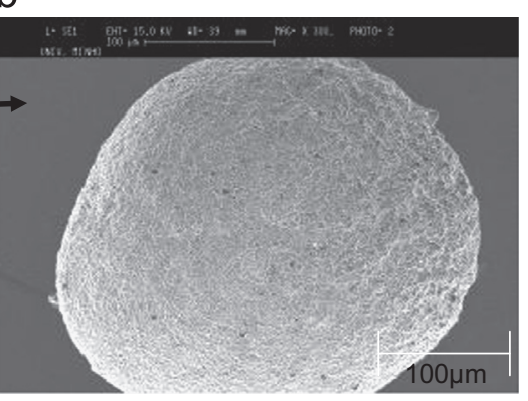

d

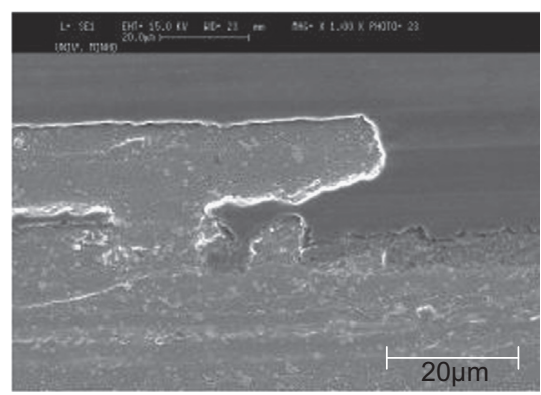

f

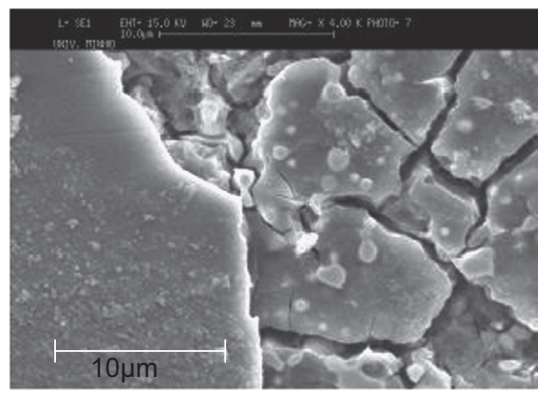

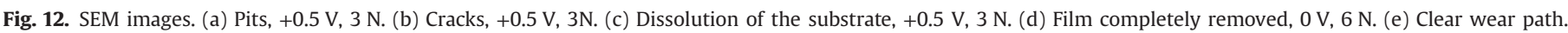
(f) Enlarged view of the worn surface.

In addition, the sample with an $r_{c}$ value of 4.1 has lower thickness in comparison with the sample with $r_{c}=1.6$, but it has less depth caused by wear. This behavior is very important because it indicates that low structural/morphological quality of the film (for example $r_{c}=4.1$ ) leads to better behavior in wear resistance. In the case of the sample with $r_{c}=1.6$, although it is thicker, the wear depth is higher than in the sample with $r_{c}=4.1$. Thus, this study reveals that the wear and corrosion volume of the 


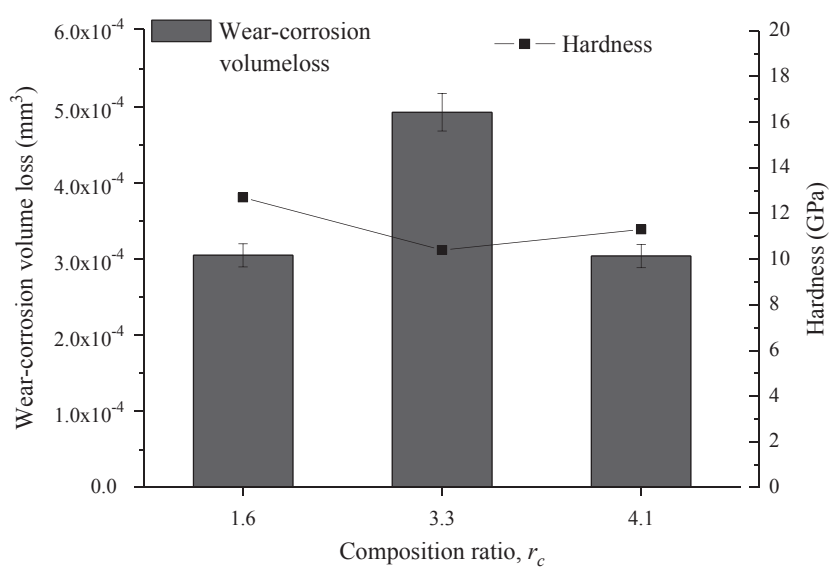

Fig. 13. Variation in wear-corrosion volume loss $\left(K_{w c}\right)$ for the selected films, showing the relationship with hardness and number of defects.

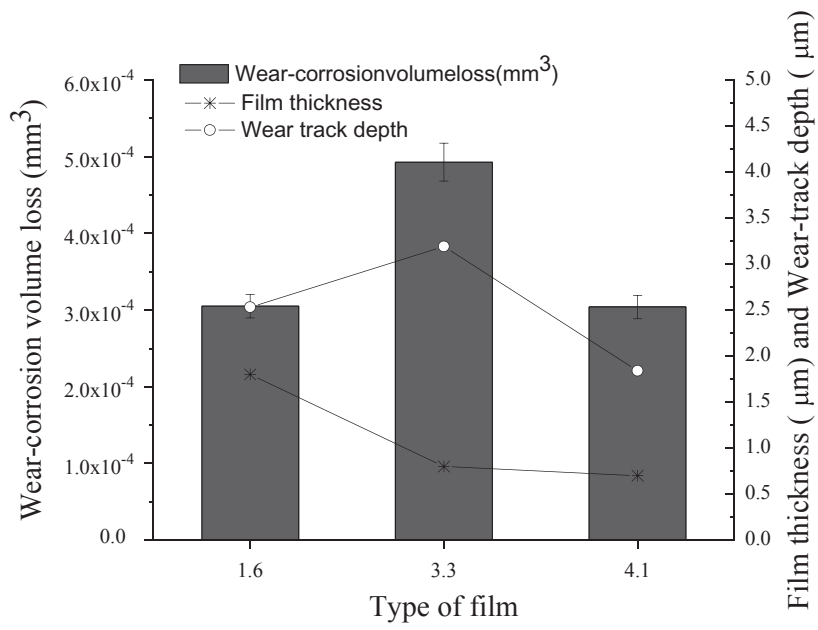

Fig. 14. Variation in wear-corrosion volume loss $\left(\mathrm{Kw}_{\mathrm{c}}\right)$ for the selected films, showing the relationship with film thickness and depth.

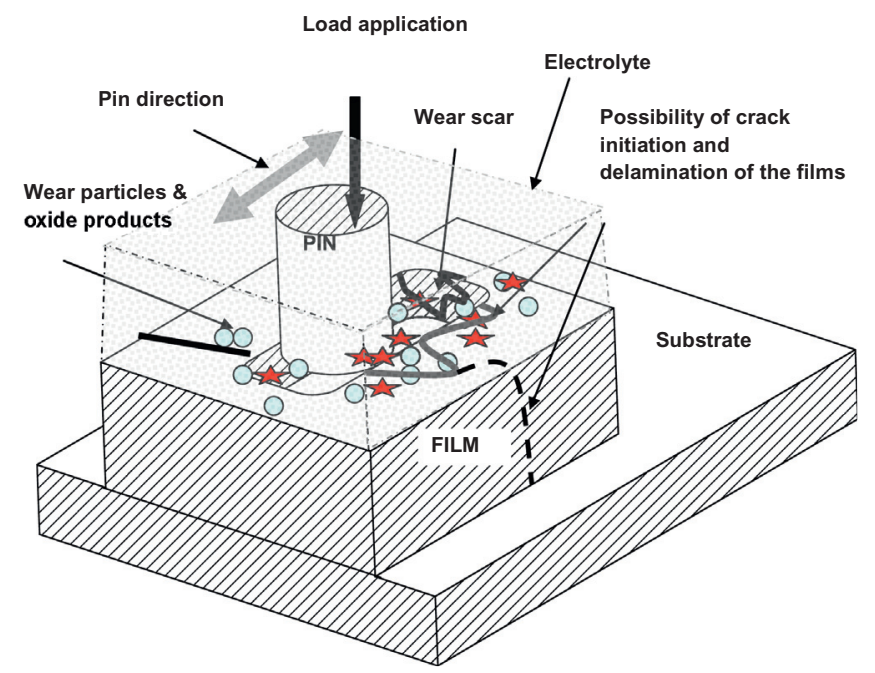

Fig. 15. Schematic diagram of the tribocorrosion process at the tribological contacts in the presence of saliva.

thin films is not directly related to hardness, thickness or the number of defects in the samples. However, such mechanical parameters have an influence on the film behavior, in accordance with film structure and test conditions, which clearly indicates that the structure and morphology of the sample can have a strong influence in the degradation behavior [25-28,33-35].

\subsection{Possible mechanisms}

A schematic diagram was developed to understand the wearcorrosion mechanisms involved in the process, as shown in Fig.15. In fact, the wear scar and driving mechanisms are closely related to the contact geometry and environment. A schematic diagram illustrates the complex conditions at the contact zone. This figure shows that the pin is under reciprocating motion in the presence of the electrolyte. During the pin motion, due to the tribological events and corrosive kinetics, metal ions and wear debris will be released to the surrounding electrolyte. The wear-corrosion mechanism will be influenced by the changes in the media and the presence of the third bodies. There is also the possibility of crack initiation, and the effect of the solution can further trigger the tribological events and accelerate the total wear mechanisms [27]. More explanations of the possible mechanisms are given in a previous work by our group $[23,24]$.

The work will be extended to analyze the influence of other mechanical and chemical parameters on the tribocorrosion process. In addition, new methodologies, such as mapping and modeling, are required to gain a broader understanding of the wear corrosion interaction and the resulting synergistic effects [29,30,32-36].

\section{Conclusions}

Based on this study of Ti-C-O-N thin film degradation, we can make the following conclusions:

- The initial corrosion results show that the thin films in the different samples can protect the substrate because they exhibit better behavior than the substrate.

- The tribocorrosion results show that the sample with $r_{c}=4.1$ exhibits better behavior.

- In the tribocorrosion tests, it is clear that all samples lost the film and the substrate was exposed, in agreement with the total wear-corrosion volume loss $\left(\mathrm{K}_{\mathrm{wc}}\right)$.

- Possible degradation mechanisms were discussed; cracking and pitting could delaminate the film. The presence of corrosion products and wear debris could be involved in the degradation process.

- The results indicate that the tribocorrosion behavior of thin films is directly related to the structure and thus the thickness, hardness and composition of the sample.

\section{Acknowledgements}

This research is supported by FEDER funds through COMPETEPrograma Operacional Factores de Competitividade and by national funds through the Fundação para a Ciência e a Tecnologia, project PTDC/CTM/69362/2006 and contract SFRH/BD/27569/2006.

\section{References}

[1] Stueber M, Albers U, Leiste H, Ulrich S, Holleck H, Barna PB, et al. Multifunctional nanolaminated PVD coatings in the system Ti-Al-N-C by combination of metastable fcc phases and nanocomposite microstructures. Surf Coat Technol 2006;200(22-23):6162-71. 
[2] Pesch P, Sattel S, Woestmann S, Ulrich S. New multifunctional PVD-coating in the material system $\mathrm{Cr}-\mathrm{BCN}-\mathrm{Si}$ for steel sheet forming. Surf Coat Technol 2005;200:1065-70.

[3] Panckow AN, Steffenhagen J, Wegener B, Dubner L, Lierath F. Application of a novel vacuum-arc ion-plating technology for the design of advanced wear resistant coatings. Surf Coat Technol 2001;138:71-6.

[4] Burmeister F, Kohn C, Kuebler R, Kleer G, Blasi B, Gombert A. Applications for TiAlN- and $\mathrm{TiO}_{2}$-coatings with nanoscale surface topographies. Surf Coat Technol 2005;200:1555-9.

[5] Carvalho P, Vaz F, Rebouta L, Cunha L, Tavares CJ, Moura C, et al. Structural, electrical, optical, and mechanical characterizations of decorative $\mathrm{ZrOxNy}$ thin films. J Appl Phys 2005;98:023715-1-8.

[6] Martin N, Banakh O, Santo AME, Springer S, Sanjinés R, Takadoum J, et al. Correlation between processing and properties of $\mathrm{TiO}_{x} \mathrm{~N}_{y}$ thin films sputter deposited by the reactive gas pulsing technique. Appl Surf Sci 2001; 185:123-33.

[7] Fenkera M, Jackson N, Spolding M, Nicole P, Schfnhut K, Gregory G, et al. Corrosion performance of PVD-coated and anodised materials for the decorative market. Surf Coat Technol 2004;188-189:466-72.

[8] Hubler R. Transition metal nitrides thin films deposition using a dynamically controlled magnetron sputtering apparatus. Surf Coat Technol 2002;158159:680-4.

[9] Niyomsoan S, Grant W, Olson DL, Mishra B. Variation of color in titanium and zirconium nitride decorative thin films. Thin Solid Films 2002:415:187-94.

[10] Hultman L. Thermal stability of nitride thin films. Vacuum 2000:1-30.

[11] Mitterer C. Borides in thin film technology. J Solid State Chem 1997;133:279-91.

[12] Mori M, Tabata A, Mizutani T. Properties of hydrogenated amorphous silicon carbide films prepared at various hydrogen gas flow rates by hot-wire chemical vapor deposition. Thin Solid Films 2006;501:177-80.

[13] Li ZG, Mori M, Miyake S, Kumagai M, Saito HY. Muramatsu Structure and properties of Ti-Si-N films prepared by ICP assisted magnetron sputtering. Surf Coat Tech 2005;193(1-3):345-9.

[14] Rebib F, Tomasella E, Aida S, Dubois M, Cellier J, Jacquet M. Electrical behaviour of $\mathrm{SiO}_{x} N_{y}$ thin films and correlation with structural defects. Applied Surface Science 2006;252(15):5607-10.

[15] Vaz F, Carvalho P, Cunha L, Rebouta L, Moura C, Alves E, et al. Goudeau Ph, Rivière JP. Property change in $\mathrm{ZrN}_{x} \mathrm{O}_{y}$ thin films: effect of the oxygen fraction and bias voltage. Thin Solid Films 2004;469-470:11-7.

[16] Vaz F, Cerqueira P, Rebouta L, Nascimento SMC, Alves EGoudeau Ph, Rivière JP. Mechanical characterization of reactively magnetron-sputtered TiN films. Surf Coat Technol 2003;174-175:197-203.

[17] Fernandes AC, Vaz F, Rebouta L, Pinto A, Alves E, Parreira NMG, Rivière JP. The influence of structure changes in the properties of $\mathrm{TiC}_{x} \mathrm{O}_{y}$ decorative thin films. Thin Solid Films 2007;515(13):5424-9.

[18] Arvinte R, Borges J, Sousa RE, Munteanu D, Barradas NP, Alves E, et al. Preparation and characterization of $\mathrm{CrN}_{\mathrm{x}} \mathrm{O}_{\mathrm{y}}$ thin films: The effect of composition and structural features on the electrical behavior. Applied Surface Science 2011;257(21):9120-4.
[19] Landolt D, Mischler S, Stemp M. Electrochemical methods in tribocorrosion: a critical appraisal. Electrochim Acta 2001;46:24-5.

[20] Stack MM, Mathew MT, Jawan H. On the construction of microabrasion maps for a steels/polymer couple in corrosive environment. Tribol Int 2005;38 (9):848-56.

[21] Ferreira SC, Ariza E, Rocha LA, Gomes JR, Carvalho Ph, Vaz F. Tribocorrosion behaviour of ZrOxNy thin films for decorative applications. Surf. Coat. Technol 2005;200:6634-9.

[22] Ariza E, Rocha LA. Structural and corrosion behaviour of stoichiometric and substoichiometric TiN thin film. Materials Science Forum 2005;492493:189-94.

[23] Mathew M T, Ariza E, Rocha LA, Fernandes AC, Vaz F. TiC $\mathrm{O}_{\mathrm{y}}$ thin films for decorative applications: Tribocorrosion mechanisms and synergism. Tribology International 2007;41(7):603-15.

24] Mathew MT, Ariza E, Rocha LA, Vaz F, Fernandes AC, Stack MM. Tribocorrosion behaviour of $\mathrm{TiC}_{x} \mathrm{O}_{y}$ thin films in bio-fluids Electrochimica Acta 2010;56 (2):929-37.

25] Chappé JM, Vaz F, Cunha L, Moura CMarco, de Lucas MC, Imhoff L, et al. Development of dark Ti(C,O,N) coatings prepared by reactive sputtering. Surf Coat Technol (2008) 10.1016/j.surfcoat 2008;05:039.

[26] Chappé JM, Fernandes AC, Cunha L, Moura C, Vaz F, Martin N, et al. TiN-based decorative coatings: colour change by addition of $C$ and $O$. Journal of Optoelectronics and Advanced Materials 2008;10(4):900-3.

27] Glocker DA, Shah SI. Handbook of Thin Film Process Technology. Bristol and Philadelphia: IOP Publishing: 2.

[28] European Standard EN 1811:1998. Reference test method for release of nicke from products intended to come into direct and prolonged contact with the skin.

[29] Mathew MT, Barão VA, Yuan JC, Assunção WG, Sukotjo C, Wimmer MA. What is the role of lipopolysaccharide on the tribocorrosive behavior of titanium? Mech Behav Biomed Mater 2012:8:71-85.

[30] Mathew MT, Runa MJ, Laurent M, Jacobs JJ, Rocha LA, Wimmer MA Construction of a tribocorrosion test apparatus for the hip joint: Validation, test methodology and analysis. Wear 2011;271(9-10):1210-9.

[31] Mathew MT, Uth T, Hallab NJ, Pourzal R, Fischer A, Wimmer MA. Tribocorrosion behavior of CoCrMo alloy for hip prosthesis as a function of loads: A comparison between two testing systems. Wear 2011;271(9-10):2651-9.

[32] D Landolt and S Mischler. Tribocorrosion of passive metals and coatings, published by Woodhead Publishing, ISBN:9781845699666.

[33] Robert WH, Yang CC, Huang CA, Chen YS. Electrochemical corrosion propertie of Ti-6Al-4V implant alloy in the biological environment. Materials Science and Engineering A 2004;380:100-9.

34] Archard JF. Contact and Rubbing of Flat Surfaces. J Appl Phys 1953;24:981.

[35] Williams JA, Hyncica AM. Abrasive wear in lubricated contacts. J Phys D: Appl Phys 1992;25:A81-90.

[36] Axen N, Jacobson S, Hogmark S, Axen N, Jacobson S, Hogmark S. Influence of hardness of the counterbody in three-body abrasive wear-an overlooked hardness effect. Tribol Int 1994;27(4):233-41. 